\title{
Compostos secundários durante a decomposição foliar de espécies arbóreas em um riacho do sul do Brasil
}

\author{
Luiz Ubiratan Hepp ${ }^{1,4}$, Rogério Delanora ${ }^{2}$ e André Trevisan ${ }^{3}$
}

Recebido em 27/08/2007. Aceito em 21/08/2008

RESUMO - (Compostos secundários durante a decomposição foliar de espécies arbóreas em um riacho do sul do Brasil). Os objetivos deste trabalho foram identificar os compostos secundários e avaliar o comportamento destes em folhas de Sebastiania commersoniana (Baill.) Smith e Downs e Eucalyptus grandis Hill ex Maiden durante diferentes estágios de decomposição em um riacho de primeira ordem do norte do Rio Grande do Sul. Foram incubadas no riacho folhas das duas espécies, sendo essas retiradas do corpo hídrico após zero, um, 30 e 60 dias para determinação da taxa de decomposição e análise química por cromatografia gasosa. Foi possível identificar 14 compostos em $S$. commersoniana e $25 \mathrm{em} E$. grandis. O ácido palmítico foi o composto mais freqüente em ambas as espécies durante o experimento, sendo que a quantidade deste e dos demais compostos identificados variou durante o período estudado. A complexidade química das folhas de E. grandis pode ter influenciado na sua decomposição, que foi mais lenta que a das folhas de $S$. commersoniana.

Palavras-chave: Eucalyptus grandis, qualidade ambiental, Sebastiania commersoniana, vegetação ribeirinha

ABSTRACT - (Secondary compounds during leaf decomposition of tree species in a stream in southern Brazil). This work aims to identify the secondary compounds and evaluate their behaviour in Sebastiania commersoniana (Baill.) Smith and Downs (Euphorbiaceae) and Eucalyptus grandis Hill ex Maiden (Myrtaceae) leaves during different decomposition stages in a first-order stream in northern Rio Grande do Sul. Leaves of the two species were incubated in the stream and were removed after 0, 1, 30 and 60 days to determine decomposition rate and perform chemical analysis by gas chromatography. Fourteen compounds in S. commersoniana and 25 in $E$. grandis were identified. Palmitic acid was the most frequent compound in both species throughout the experiment; the amount of this acid and the other compounds varied during the study period. The chemical complexity of $E$. grandis leaves may have influenced their decomposition, which was slower than that of $S$. commersoniana leaves.

Key words: environmental quality, Eucalyptus grandis, riparian vegetation, Sebastiania commersoniana

\section{Introdução}

Riachos que apresentam vegetação ribeirinha bem desenvolvida dependem da entrada de energia alóctone para a manutenção das comunidades biológicas nos ecossistemas aquáticos (Trevisan \& Hepp 2007), que é muitas vezes regulada pela quantidade (Bastardo 1986) e qualidade de detrito presente (Graça \& Canhoto 2006). Assim, os processos de decomposição assumem papel importante na dinâmica destes ecossistemas, pois apresentam relações diretas com o fluxo de matéria e energia dentro desses ambientes (Odum 2001). Vanotte et al. (1980) afirmam, em seu conceito de continuidade fluvial, que os mananciais de pequeno porte são intensivamente influenciados pela vegetação ribeirinha, pois, nesses locais, a energia oriunda do material alóctone é muitas vezes maior que a produção autóctone.
A decomposição do material vegetal depende basicamente de fatores climáticos, da qualidade do detrito, de variáveis ambientais e da disponibilidade e ação de decompositores (Coûteaux et al. 1995; Gartner \& Cardon 2004; Trevisan \& Hepp 2007). No início do processo de decomposição, a composição química do material alóctone dificulta o seu aproveitamento pelos herbívoros. Assim, a colonização inicial do detrito se dá por microorganismos decompositores, principalmente bactérias e fungos filamentosos, que serão os responsáveis pelas primeiras lises do material vegetal, possibilitando uma posterior colonização por invertebrados fragmentadores (Spänhoff \& Meyer 2004; Gonçalves Jr. et al. 2006).

Os compostos secundários são produzidos e secretados por células após processos bioquímicos envolvendo compostos químicos primários da planta.

\footnotetext{
1 Universidade Regional Integrada do Alto Uruguai e das Missões, Departamento de Ciências Biológicas, Av. Sete de Setembro 1621, 99700-000 Erechim, RS, Brasil

2 Universidade Regional Integrada do Alto Uruguai e das Missões, Centro Tecnológico, Av. Sete de Setembro 1621, $99700-000$ Erechim, RS, Brasil

3 Universidade Federal de Santa Maria, Programa de Pós-Graduação em Ciências Biológicas, Biodiversidade Animal, Av. Roraima 1000, Cidade Universitária, Bairro Camobi, 97105-900 Santa Maria, RS, Brasil

4 Autor para correspondência: lhepp@uri.com.br
} 
Estes compostos possuem distintas funções ecológicas na planta, como alelopatia, ação atrativa ou repelente a organismos (Swain 1977; Dearing et al. 2001). Rodrigues (2006) cita que algumas espécies vegetais possuem defesa química, pronunciada pela presença de metabólitos secundários que, em ambientes aquáticos, podem acelerar ou retardar o processo de decomposição. A composição química em folhas durante a decomposição é pouco estudada, ainda que estas informações sejam relevantes para a compreensão de processos ecológicos nos diferentes ecossistemas (Käinulainen \& Holopainen 2002; Campanella \& Bertiller 2008).

Estudos que avaliam a liberação de compostos químicos por plantas durante a decomposição são ainda incipientes, frente ao elevado número de espécies de plantas e à grande diversidade das químicas emitidas para o ambiente (Souza et al. 2002). O conhecimento da dinâmica de compostos químicos durante a decomposição facilita o entendimento sistêmico de alguns aspectos do ecossistema aquático, facilitando a compreensão das interações entre os seus componentes bióticos e abióticos. Além disso, grandes áreas estão sendo cultivadas com espécies exóticas para produção de madeira e seus derivados, com consequiências desconhecidas sobre o ecossistema. No sul do Brasil, espécies do gênero Eucalyptus vêm sendo amplamente cultivadas, enquanto Sebastiania commersoniana é uma espécie de ocorrência natural e abundante nas regiões ribeirinhas da região Norte do Rio Grande do Sul (Lorenzi 2000). O estudo constitui-se em um primeiro registro sobre compostos secundários durante diferentes estágios de decomposição de folhas em sistemas aquáticos no país, em especial na região Subtropical. Os objetivos deste estudo foram i) identificar os compostos secundários presentes em folhas de Sebastiania commersoniana (Baill.) Smith e Downs e Eucalyptus grandis Hill ex Maiden durante diferentes estágios de decomposição em riachos, e ii) avaliar o comportamento destes compostos durante o processo de decomposição em um ambiente aquático, baseado na sua disponibilidade durante o período de estudo.

\section{Material e métodos}

Área de Estudo - O estudo foi realizado no município de Erechim, RS, norte do Rio Grande do Sul, situado a $27^{\circ} 37^{\prime} 54^{\prime \prime}$ S e $52^{\circ} 16^{\prime} 52^{\prime \prime} \mathrm{N}$. A altitude é de $720 \mathrm{~m}$, temperaturas médias de $18{ }^{\circ} \mathrm{C}$ e a pluviosidade anual média é de $1.800 \mathrm{~mm}$. O local apresenta uma faixa de vegetação ribeirinha com largura aproximada de $20 \mathrm{~m}$ em cada uma das margens, com o predomínio de constituintes da Floresta Ombrófila Mista, destacando espécies como Araucaria angustifolia (Bertol.) Kuntze,
Ocotea sp., Cabralea canjerana (Vellozo) Martius e Sebastiania commersoniana, utilizada neste experimento. $\mathrm{O}$ riacho estudado é um tributário de primeira ordem do Rio Suzana $\left(27^{\circ} 36^{\prime} 43,5^{\prime \prime} \mathrm{S}\right.$ e $52^{\circ} 14^{\prime} 5,4^{\prime \prime} \mathrm{W} ; 718 \mathrm{~m}$ de altitude). O substrato predominante no fundo do córrego são pedras, areia e folhiço, a largura média é de $0,50 \mathrm{~m}$ e a profundidade de $0,15 \mathrm{~m}$. A vazão média durante o experimento foi de $0,011 \pm 0,007 \mathrm{~m}^{3} \mathrm{~s}^{-1}$, a temperatura de $20,1 \pm 1,0{ }^{\circ} \mathrm{C}$, o pH manteve-se em torno da neutralidade $(6,8 \pm 0,8)$ e as águas apresentaram-se bem oxigenadas $\left(8,02 \pm 1,40 \mathrm{mg} \mathrm{L}^{-1}\right)$.

Experimento de decomposição - Foram coletadas folhas senescentes de Sebastiania commersoniana e Eucalyptus grandis, no outono/2004, sendo secas em estufa a $35^{\circ} \mathrm{C}$ para posterior utilização nos sacos de decomposição. Para o experimento, foram utilizados sacos de malha plástica de $20 \times 30 \mathrm{~cm}$, com 2,0 mm de abertura de malha (Pompêo \& Moschini-Carlos 2003), sendo cada um preenchido com $50 \mathrm{~g}$ de folhas de $S$. commersoniana e E. grandis, individualmente. Entre os meses de setembro e outubro/2004, os sacos foram dispostos no riacho, de forma alternada, ao longo de ambas as margens, a fim de minimizar os efeitos da velocidade de correnteza sobre os sacos com as folhas. Um saco correspondente a cada espécie vegetal foi retirado, para a realização das análises químicas, de maneira aleatória, no dia da instalação e após um, 30 e 60 dias.

Análises químicas - $\mathrm{O}$ detrito retirado periodicamente do riacho foi seco, pesado e triturado para realização das análises químicas. $\mathrm{O}$ teor de matéria orgânica livre de cinzas foi determinado por gravimetria, a partir da incineração do detrito vegetal a $550^{\circ} \mathrm{C}$ durante seis horas. Para determinação do coeficiente de decomposição, ajustaram-se os valores ao modelo exponencial negativo $\mathrm{Wt}=\mathrm{W}_{0} \cdot \mathrm{e}^{-\mathrm{kt}}$, onde $\mathrm{Wt}$ é o peso remanescente no tempo $\mathrm{t}$ (em dias), $\mathrm{W}_{0}$ é a massa inicial e $\mathrm{k}$ é o coeficiente de decomposição (Webster \& Benfield 1986). O teor de polifenóis totais foi determinado, a partir da extração de $500 \mathrm{mg}$ de amostra com metanol 50\%, por espectrofotometria, de acordo com o método de FolinCiocalteu, sendo os resultados expressos em Unidade de Densidade Óptica (UDO g ${ }^{-1} \mathrm{MS}$ ) (Bärlocher \& Graça 2005).

Para a análise cromatográfica, a extração foi feita a partir de uma fração de $100 \mathrm{mg}$ da amostra seca e triturada das duas espécies, com $1 \mathrm{~mL}$ de Metanol 99\%, em termoreator à temperatura de $100^{\circ} \mathrm{C}$, durante 30 minutos. Após este processo, efetuou-se a filtração através de seringas, com duas camadas de papel filtro de celulose. Ao final da filtração, foi adicionado mais $1 \mathrm{~mL}$ de Metanol, com o propósito de lavar o resíduo retido nas cubetas. A composição orgânica da solução foi determinada por 
Cromatografia Gasosa com Espectro de Massas (GCMS), com um sistema Shimadzu QP5050A. O volume de amostra injetado foi de $1 \mu \mathrm{L}$ com razão de Split 1/8. A separação dos compostos do extrato foi realizada em coluna DB-WAX (30 $\mathrm{m} \times 0,25 \mathrm{~mm}$ ID) com temperatura inicial de $40{ }^{\circ} \mathrm{C}$ ( $3 \mathrm{~min}$.) e um gradiente de aquecimento à taxa de $8{ }^{\circ} \mathrm{C} \mathrm{min}^{-1}$, até $250{ }^{\circ} \mathrm{C}$ (temperatura final - 10 min.), totalizando um tempo de corrida de 39,25 min. Os componentes da amostra eluíram através da coluna com um fluxo de $1,0 \mathrm{~mL} \mathrm{~min}^{-1}$. A identificação dos compostos foi feita por comparação dos espectros de massa de padrões disponíveis na biblioteca existente no software do equipamento, além da utilização de padrões externos.

\section{Resultados e discussão}

Ao final do período (60 dias) de experimento de decomposição, as folhas Eucalyptus grandis apresentaram massa remanescente de 75,1\% $\left(\mathrm{k}=-0,005 \mathrm{dia}^{-1}\right.$, $\mathrm{R}^{2}=0,99$ ), enquanto para Sebastiania commersoniana essa massa era de $18,5 \%\left(k=-0,028 \mathrm{dia}^{-1}, \mathrm{R}^{2}=0,95\right)$, caracterizando uma decomposição $(\mathrm{k})$ cinco vezes mais lenta da espécie exótica (Fig. 1). As taxas de decomposição em riachos podem ser influenciadas pelo efeito físico gerado pela correnteza do riacho, pela composição química do detrito e pela ação de decompositores. Estudos de decomposição com folhas de Eucalyptus spp. demonstram que esta espécie possui uma taxa de decomposição mais lenta em comparação com outras espécies arbóreas, ocasionada, possivelmente, pela variedade de compostos químicos constituintes da folha (Graça et al. 2002).

Os teores de polifenóis totais foram maiores em folhas de Eucalyptus grandis no dia de instalação do experimento (17,1 UDO g g-1 MS) em relação a Sebastiania commersoniana (11,1 UDO g $\left.{ }^{-1} \mathrm{MS}\right)$. No entanto, ao final do período de experimento, estes compostos não foram observados nas folhas de ambas as espécies (Fig. 1). Os fenóis são um dos principais grupos de compostos secundários em plantas, que funcionam como defesas contra herbívoros e patógenos (Hättenschwiler \& Vitousek 2000). Por esta razão, concentrações elevadas destes compostos contribuem para um retardamento da decomposição do detrito, pois dificultam a colonização por microorganismos e posterior fragmentação por invertebrados (Bärlocher \& Graça 2005; Trevisan \& Hepp 2007).

O resultado observado nas folhas de Eucalyptus grandis pode ser atribuído às características químicas do próprio material vegetal. A composição química das folhas de Sebastiania commersoniana e E. grandis durante o processo de decomposição foi distinta, apresentando uma variação de compostos orgânicos majoritários em cada uma das espécies analisadas. Foi possível identificar 38 compostos, sendo 14 em S. commersoniana e 25 em E. grandis (Tab. 1). Destes, somente três foram identificados em ambas as espécies vegetais (ácido acético, ácido palmítico e fitol). No período inicial do experimento, foi observada maior quantidade de picos na porção final do cromatograma (após 30 min.) para ambas as espécies, o que representa substâncias de maior massa molecular. Com a análise das amostras provenientes de períodos mais avançados de decomposição, a quantidade dos picos finais foi diminuindo e resultando em novos picos na porção inicial do cromatograma (10 a $20 \mathrm{~min}$.), caracterizando a clivagem das substâncias mais complexas em substâncias mais simples (menor massa molecular) (Fig. 2-3).

A matéria orgânica vegetal é decomposta basicamente por microorganismos que possuem condições bioquímicas de degradar compostos mais resistentes, como lignina e compostos fenólicos. Estas substâncias regulam a atividade da fauna microbiana

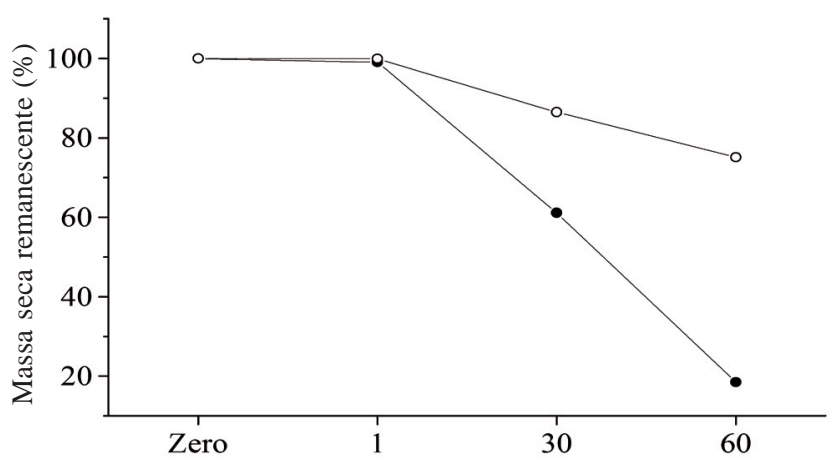

B

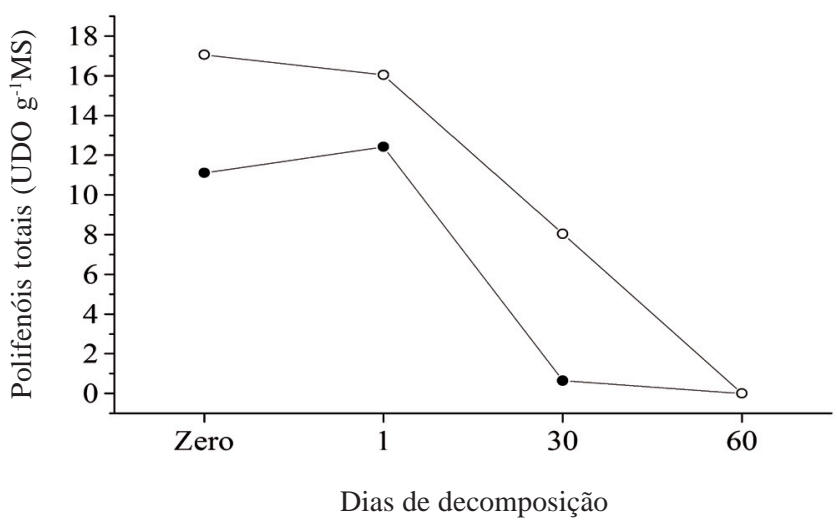

Figura 1. Massa seca remanescente (A) e polifenóis totais (B) nas folhas de $S$. commersoniana (Baill.) Smith e E. grandis Hill ex Maiden durante a decomposição em riacho $(-\bullet-=S$. commersoniana; $-\mathrm{O}-=$ E. grandis $)$. 
Tabela 1. Compostos secundários identificados em folhas de Sebastiania commersoniana (Baill.) Smith e Downs e Eucalyptus grandis Hill ex Maiden durante a decomposição em um riacho do Sul do Brasil.

\begin{tabular}{|c|c|c|c|}
\hline Compostos & empo de retenção (minutos) & $\begin{array}{c}\text { Sebastiania commersoniana } \\
\text { Área do Pico (\%) }\end{array}$ & Eucalyptus grandis \\
\hline (+)-Aromadendreno & 15,433 & & 2,48 \\
\hline 1-Borneol & 16,900 & & 0,72 \\
\hline 1-Hexanol & 22,833 & 2,69 & \\
\hline 2-Hexadecanol & 29,583 & 14,92 & \\
\hline 2-Metil-2-Hepteno-6-One & 19,933 & & 16,83 \\
\hline 3,5-Dihydroxy-2-Methyl-5,6-Dihydropyran-4-One & 24,483 & 6,93 & \\
\hline 3-Hydroxybutanal & 24,483 & & 0,79 \\
\hline 3-Penten-2-ol & 31,842 & & 4,10 \\
\hline 4-Hepteno-3-one & 27,067 & 5,82 & \\
\hline 6-Metil-5-Hepteno-2-One & 19,225 & & 8,01 \\
\hline 6-Metil-5-Hepteno-2-One B & 17,317 & & 0,90 \\
\hline $9,12,15$-Octadecatrienal & 28,083 & 3,79 & \\
\hline Acetato Dihidrocarveol & 22,283 & & 1,58 \\
\hline Ácido Acético & 12,725 & 9,48 & 1,12 \\
\hline Acido Dihidrohidnocarpico & 20,417 & 3,51 & \\
\hline Ácido Palmítico & 31,450 & 27,83 & 18,20 \\
\hline Aldeído Palmítico & 31,442 & 2,37 & \\
\hline Aldeído Stearil & 20,017 & 6,78 & \\
\hline Alpha-Terpineol & 16,833 & & 0,26 \\
\hline Beta-Eudesmol & 24,092 & & 2,56 \\
\hline Dioxide-1-Limoneno & 26,442 & & 2,43 \\
\hline Dioxide-4-Limoneno & 21,342 & & 2,12 \\
\hline Etil palmitato & 24,258 & 2,78 & \\
\hline Eucaliptol & 8,292 & & 5,56 \\
\hline Exo-Fenchol & 15,029 & & \\
\hline Fenol & 21,083 & 0,98 & \\
\hline Fitol & 28,208 & 7,21 & 7,06 \\
\hline Glicerol & 24,967 & 7,62 & \\
\hline Globulol & 22,192 & & 8,09 \\
\hline Guaiol & 23,975 & & 1,18 \\
\hline 1-Limoneno & 7,967 & & 1,69 \\
\hline Metil 2-Acetylhydroxypalmitato & 27,267 & & 7,06 \\
\hline Mircenol & 22,667 & & 1,33 \\
\hline Pinocarvona & 14,819 & & \\
\hline Propilethinylcarbinol & 21,650 & & 1,25 \\
\hline Terpineol-4 & 15,358 & & 0,89 \\
\hline trans-Pinocarveol & 16,108 & & 1,10 \\
\hline Undecanal & 26,817 & & 2,69 \\
\hline
\end{tabular}

durante o processo de degradação, pelo seu caráter inibidor (Käinulainen \& Holopainen 2002; Silva \& Costa 2004). O ácido tânico, óleos, fenóis, furfural, ácido acético e compostos aromáticos dificultam o desenvolvimento do micélio de fungos hifomicetos, os quais são os principais responsáveis pelas etapas iniciais da decomposição foliar (Graça et al. 2002), além de serem muito comuns em material vegetal em decomposição (Carvalho et al. 2005). Estes compostos foram identificados pela análise cromatográfica no detrito de ambas as espécies estudadas.

Em Sebastiania commersoniana ácido palmítico, ácido acético e 2-hexadecanol foram os compostos com maior porcentagem de área assinalada pelo cromatograma, revelando a maior disponibilidade destes compostos nas folhas (Tab. 1, Fig. 2). Branco \& Pizzolatti (2002) detectaram em Sebastiania argutiden Pax \& Hoffm. ésteres metílicos, ácidos alifáticos e hidrocarbonetos, sendo que ácido palmítico foi constante nas folhas desta espécie. O ácido acético apresentou-se em maiores quantidades no início de experimento, com decréscimo nos dias subseqüentes. O mesmo comportamento foi observado para o ácido palmítico. Este ácido é um lipídio de cadeia longa que possui uma capacidade muito grande de interferir na síntese de ATP bacteriano, resultando em um decréscimo da concentração deste composto (Mendes et al. 2005). A presença de ácido palmítico nos detritos estudados pode atuar como inibidor da colonização de microorganismos, retardando a decomposição do detrito vegetal. 
Silva \& Costa (2004) citam que as folhas de espécies do gênero Eucalyptus são muito complexas quimicamente, podendo ser esta uma das explicações para o elevado número de compostos identificados pela análise comatográfica. Eucalyptus grandis apresentou um cromatograma caracterizado, principalmente, pela presença de ácido palmítico (Tab. 1, Fig. 3), o qual apresentou um decréscimo no decorrer do processo de decomposição. Limoneno e acetato de palmitil tiveram comportamento semelhante, mas foi observado um incremento destes compostos nas primeiras 24 horas de decomposição. Graça et al. (2002) comentam que a composição química de folhas de Eucalyptus interfere na colonização de microorganismos, devido à presença de óleos essenciais e outros compostos químicos. Silva
\& Costa (2004) corroboram esta informação, pelo fato de citarem que as folhas da maioria das espécies de Eucalyptus possuem compostos alelopáticos que prejudicam o desenvolvimento de microorganismos, impedindo a colonização e posterior degradação. Tais compostos são associados às defesas da espécie contra herbívoros e agentes patogênicos, mas podem, potencialmente, interferir negativamente nos processos de decomposição da matéria orgânica em áreas de monocultura do eucalipto. Em se tratando de riachos, a manutenção de matas ciliares nativas nas áreas de preservação permanente pode funcionar como filtro, evitando que folhas de eucalipto se acumulem a ponto de comprometer os processos naturais de decomposição da matéria orgânica que venha a se depositar no leito. É

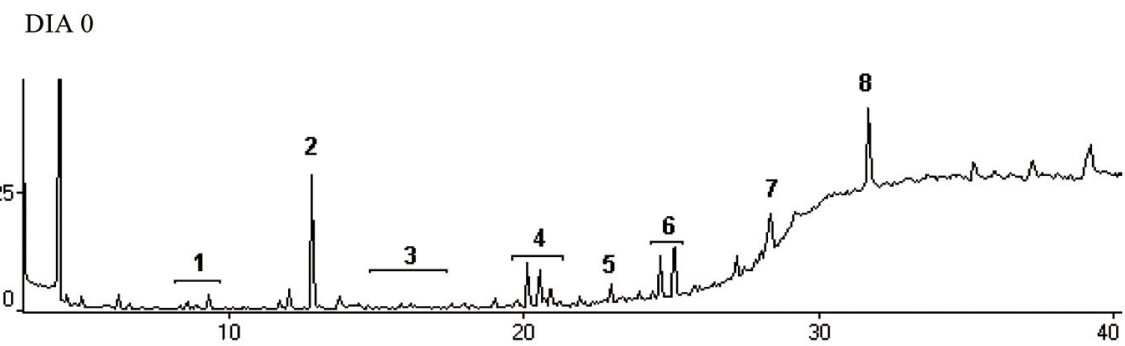

DIA 1

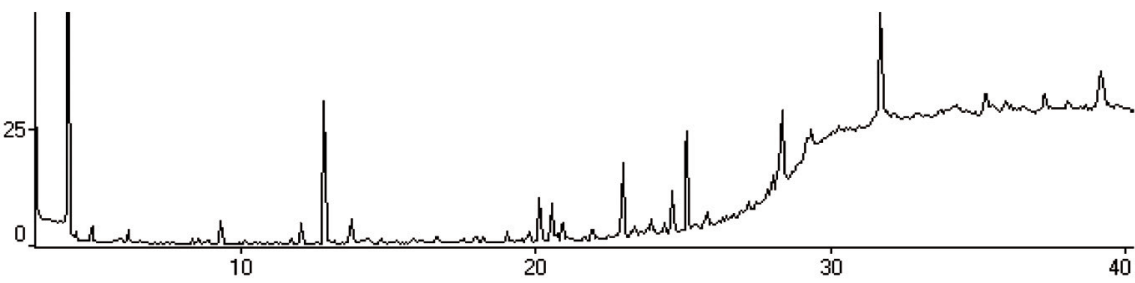

DIA 30

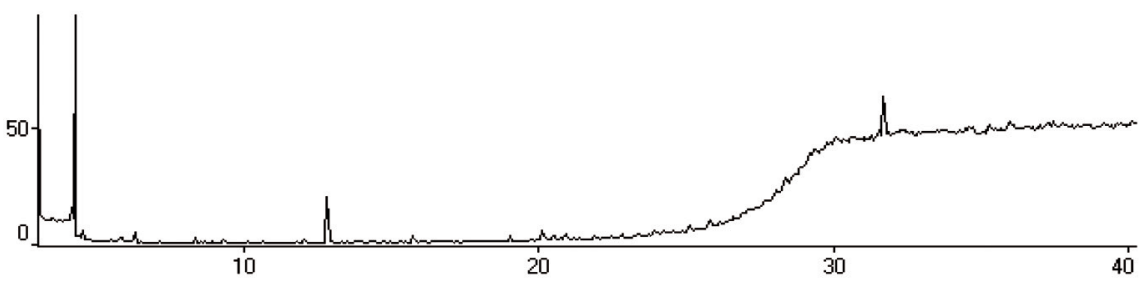

DIA 60

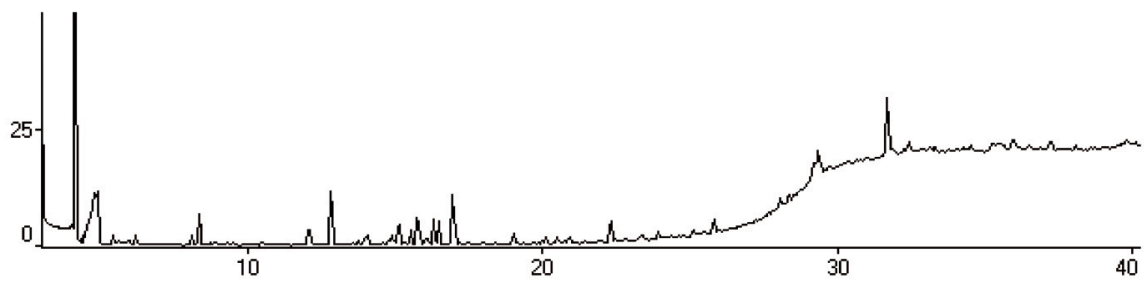

Figura 2. Cromatogramas referentes à decomposição de folhas Sebastiania commersoniana em riachos após zero (B0), 1 (B1), 30 (B30) e 60 (B60) dias de imersão. Grupo (Gr.) 1. sulfeto de butila; Gr.2. ácido acético; Gr.3. fenchol, trans-cariofileno, pinocarveol, isoborneol, alfaterpineol; Gr. 4. octadecanal (aldeído), ácido 4-hexenóico, ácido octadecanóico; Gr. 5. hexanol; Gr. 6. piran-4-one-2,3-dihidro-3,5,dihidroxi6-metil, 1,2,3,propanetriol (glicerol); Gr. 7. fitol; Gr.8. ácido palmítico. 
possível que compostos semelhantes aos detectados na decomposição de folhas de eucalipto ocorram também em espécies nativas da mesma família (Myrtaceae), reconhecidamente rica em compostos secundários. Mas, tais compostos seriam diluídos em condições de florestas naturais ou em plantios heterogêneos.

A pinocarvona e o exo-fenchol não estão presentes na folha de Eucalyptus grandis. No entanto, sua liberação ocorreu imediatamente no dia subseqüente à sua exposição ao riacho e continuou até o final do monitoramento. Pinocarvona, detectada logo no primeiro dia de monitoramento (pico 26; Fig 3), é derivada da oxidação do limoneno por microorganismos em processo natural. Esses terpenos e seus derivados oxigenados são muito usados pelas indústrias de fragrâncias e, por isso, a síntese desses compostos através de processo biológico se constitui numa alternativa atraente do ponto de vista industrial, não só pelo fato desses processos serem naturais, mas por oferecerem a possibilidade mercadológica da rotulagem natural (Carvalho et al. 2005).

A variedade de compostos secundários identificados nas folhas de Sebastiania commersoniana e Eucalyptus grandis foi distinta, sendo a segunda mais complexa quimicamente, tendo sido possível identificar 25 compostos. Dentre os 38 compostos secundários identificados nas duas espécies, apenas três foram identificados em ambas as espécies (ácido acético, ácido palmítico e fitol). O comportamento de liberação dos compostos secundários foi peculiar em ambas as
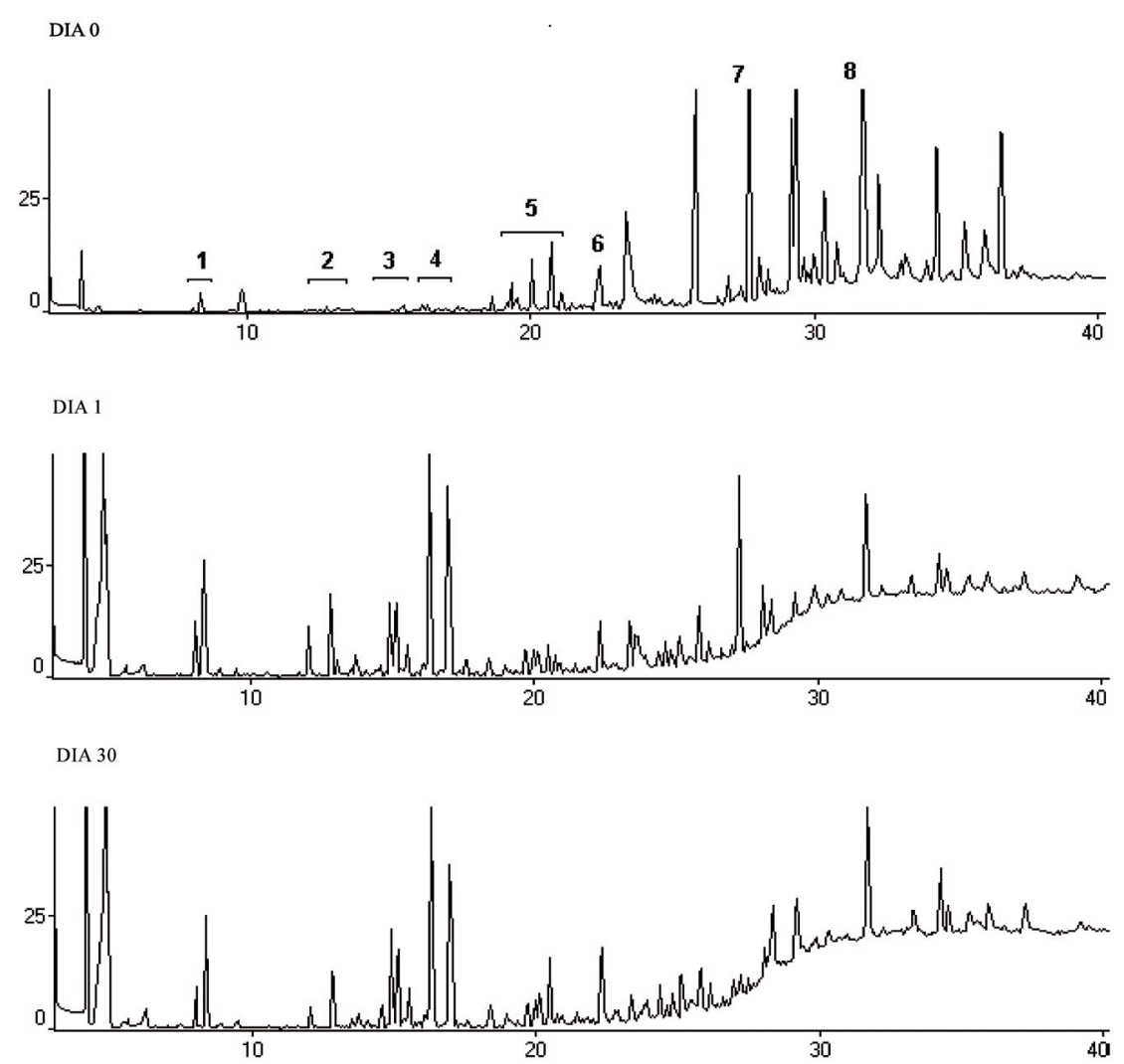

DIA 60

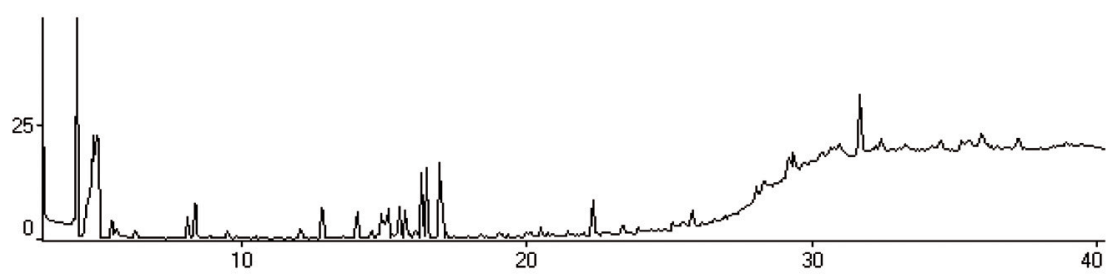

Figura 3. Cromatogramas referentes à decomposição de folhas de Eucalyptus grandis em riachos após zero (EU0), 1 (EU1), 30 (EU30) e 60 (EU60) dias de imersão. Grupo (Gr.) 1. limoneno, acetato de palmitil; Gr.2. dimetil oxalato, ácido acético; Gr.3. pinocarvona, fenchol, aromadendreno; Gr. 4. pinocarveol, alfa-terpineol, 1-borneol; Gr.5. dióxido de limoneno, aldeído palmítico, n-octanal dimetilacetal; Gr. 6. globulol; Gr. 7. 5-(hidroximetil) furfural, Gr.8. ácido palmítico. 
espécies estudadas. A maioria dos compostos apresentou um decréscimo em suas quantidades, definido pela área dos picos no decorrer do período experimental, acompanhando a perda de matéria orgânica. De maneira geral, a desaparecimento de picos durante o processo de decomposição é explicado pela liberação e diluição das substâncias pela água ou até mesmo pela transformação destas por microorganismos e invertebrados. A diversidade de substâncias orgânicas encontradas em ambas as espécies estudadas, mas principalmente em $E$. grandis, reforça a importância do material alóctone na dinâmica de nutrientes e da biota aquática, principalmente em ambientes de pequena ordem. A grande variabilidade nos compostos, inclusive alguns com atividade inibitória sobre organismos decompositores, demonstra que diferentes espécies apresentam contribuição distinta para a ciclagem de nutrientes e manutenção das comunidades bióticas, importantes componentes da integridade ambiental dos ecossistemas.

\section{Agradecimentos}

Os autores são gratos à Profa. Dra. Elisabete Maria Zanin e aos revisores anônimos, pelas importantes sugestões na redação e estruturação deste artigo.

\section{Referências bibliográficas}

Bärlocher, F. \& Graça, M.A.S. 2005. Total phenolics. In: M.A.S. Graça; F. Barlocher \& M. Gessner (eds.). Methods to study litter decomposition: a pratical guide. New York, Springer.

Bastardo, H. 1986. Actividad microbiana durante la decomposición de gramineas tropicales en sabanas inundables de los Ilanos venezolanos.Colóquio regional sobre matéria orgânica do solo. Acta Biologica Venezuelana 12: 66-71.

Branco, A. \& Pizzolatti, M.G. 2002. CGAR e CGAR-EM na análise de constituintes químicos isolados do extrato hexânico de Sebastiania argutidens (Euphorbiaceae). Química Nova 25: 15-19.

Campanella, M.V. \& Bertiller, M.B. 2008. Plant phenology, leaf traits and leaf litterfall of contrasting life forms in the arid Patagonian Monte, Argentina. Journal of Vegetation Science 19: $75-85$

Carvalho, G.B.M.; Ginoris, Y.P.; Silva, C.C.; Candido, E.J. \& Silva, J.B.A. 2005. Avaliação preliminar do tratamento do hidrolizado hemicelulósico de eucalipto para fins bioquímicos. Analytica 17: 33-37.
Coûteaux, M.M.; Bottner, P. \& Beg, B. 1995. Litter decompositon, climate and litter quality. Tree 10: 63-66.

Dearing, M.D.; Mangione, A.M. \& Karasov, W.H. 2001. Plant secondary compounds as diuretics: an overlooked consequence. American Zoologist 41: 890-901.

Gartner, T.B. \& Cardon, Z.G. 2004. Decomposition dynamics in mixed-species leaf litter. Oikos 104: 230-246.

Gonçalves Jr., J.F.; França, J.S.; Medeiros, A.O.; Rosa, C.O. \& Callisto, M. 2006. Leaf breakdown in a tropical stream. International Review Hydrobiology 91: 164-177.

Graça, M.A.S.; Pozo, J; Canhoto, C. \& Elosgi, A. 2002. Effects of Eucalyptus plantation on detritus, decomposers, and detritivores in streams. The Scientific World 2: 1173-1185.

Graça, M.A.S. \& Canhoto, C. 2006. Leaf litter processing in low order streams. Limnetica 25: 1-10.

Hättenschwiller, S. \& Vitousek, P.M. 2000. The role of poliphenols in terrestrial ecosystem nutrient cycling. Tree 15: 238-243.

Käinulainen, P. \& Holopainen, J.K. 2002. Concentrations of secundary compounds in Scot pine needles at different stages of decomposition. Soil Biology \& Biochemistry 34: 37-42.

Lorenzi, H. 2000. Árvores Brasileiras: Manual de Identificação e Cultivo de Plantas Arbóreas do Brasil. v.1. Nova Odessa, Ed. Plantarum.

Mendes, A.A.; Castro, H.F.; Pereira, E.B. \& Furigo Júnior, A. 2005. Aplicação de lipases no tratamento de águas residuárias com elevados teores de lipídeos. Química Nova 28: 296-305.

Odum, E.P. 2001. Fundamentos de Ecologia. Lisboa, Fundação Calouste Gulbenkian.

Pompêo, M.L.M. \& Moschini-Carlos, V. 2003. Macrófitas Aquáticas e Perifíton: Aspectos ecológicos e metodológicos. São Carlos, SP, RiMA.

Rodrigues, G.G. 2006. Decomposição foliar em sistemas ecológicos. Pp. 732-736. In: J.E.A. Mariath \& R.P. Santos. Os avanços da Botânica no início do Século XXI. Porto Alegre, Sociedade Botânica do Brasil.

Silva, A.C. \& Costa, A.S.V. 2004. Decomposição de partes vegetativas de eucalipto (Eucalyptus grandis) submetidas a extratos de diferentes solos. Revista Acadêmica: ciências agrárias e ambientais 2: 11-20.

Souza, S.R.; Vasconcellos, P.C.; Mantovani, W. \& Carvalho, L.R.F. 2002. Emissão por folhas de Ficus benjamina L. (Moraceae) de compostos orgânicos voláteis oxigenados. Revista Brasileira de Botânica 25: 413-418.

Spänhoff, B. \& Meyer, E.I. 2004. Breakdown rates of wood in streams. Journal of North American Benthological Society 23: 189-197.

Swain, T. 1977. Secondary compounds as protective agents. Annual Review Plant Physiology 28: 479-501.

Trevisan, A. \& Hepp, L.U. 2007. Dinâmica de componentes químicos vegetais e fauna associada ao processo de decomposição de espécies arbóreas em um riacho do norte do Rio Grande do Sul. Neotropical Biology and Conservation 2: 54-60.

Vanotte, R.L.; Minshall, K.W.; Cummins, J.R.; Sedell, J.R. \& Cushing, C.F. 1980. The River Continuum Concept. Canadian Journal Fish of Fisheries and Aquatic Sciences 37: 817-822.

Webster, J.R. \& Benfield, E.F. 1986. Vascular plant breakdown in freshwater ecosystems. Annual Review of Ecology and Systematics 17: 567-594. 